BMJ Open Sport \& Exercise Medicine

\title{
A little bit more about Popper's philosophy
}

Fernando A M S Pompeu ${ }^{1,2}$

To cite: Pompeu FAMS. A little bit more about Popper's philosophy. BMJ Open Sport \& Exercise Medicine 2018;4:e00401. doi:10.1136/ bmjsem-2018-000401

Accepted 31 May 2018
${ }^{1}$ Physical Education Postgraduate Program, Rio de Janeiro Federal University, Rio de Janeiro, Brazil ${ }^{2}$ History and Philosophy Science Department (Visiting Scholar), Cambridge University, Cambridge, UK

Correspondence to Dr Fernando A M S Pompeu; fpompeu@eefd.ufrj.br

\section{BACKGROUND AND AIM}

Professor Robergs recently raised issues based on Popper's philosophy about the Central Governor Model (CGM), whereby he concluded that the CGM is not a true scientific theory. Thus, he started his paper with Popper's demarcation criterion and finished this showing several ad hoc hypotheses that changed the CGM. ${ }^{1}$

Unhappily, Robergs made a few mistakes about Popper's work. The most important problem happened when he mixed up Popper's and Kuhn's ideas and vocabularies. ${ }^{1}$ These philosophers had a very different understanding about the truth and consequently about the Science. Kuhn believed that truth was like an agreement among scientists about the best theory. For him, this agreement depended on the specific time and space circumstances. ${ }^{2}$

On the other hand, for Popper, this interpretation was a misunderstanding about truth and certainty concepts. Moreover, Popper advised that if everyone had his/her own truth, according to the situation, the truth would lose its meaning. In addition, for Popper, when a scientist is satisfied with a 'normal science', we should feel sorry for his/ her bad education."

\section{METHODS}

For Popper, the Science Failure springs up because induction logic is applied in Science. Different from deduction, which can transfer the truth from a universal statement to a particular conclusion, induction comes from a particular observation to a universal statement. In that case, scientists should observe a phenomenon at least a few times and subsequently proclaim a universal statement. But there is no guarantee that phenomenon will occur again just because it happened several times in the past. ${ }^{34}$ Another problem with induction relates to the link between cause and effect. This link is only concluded in the scientist's mind. The scientist can only see one phenomenon before another. ${ }^{4}$
Sir Karl Popper proposed to solve this failure of science by using a syllogism to show a logic mistake by finding a negative conclusion from a positive premise. This philosopher used the statement that "every swan is white" to explain his reasoning. This statement is impossible to prove without circumscribing it in space and time. Thus, it is impossible to check its truthfulness and consequently it drives scientists to use probability or statistical significance. Nevertheless, when a scientist finds a black swan, his statement is refused with absolute certainty. In this way, experiments must be designed to test if a hypothesis should be refused. ${ }^{4}$ This is Popper's demarcation criterion for a scientific theory. Theories that cannot be refused, like Psychoanalysis or Scientific Communism, are called doctrines. ${ }^{34}$

\section{RESULTS AND CONCLUSION}

In Hill's theory, there is a plateau of oxygen consumption because the cardiovascular system cannot deliver oxygen to muscles' demand and as a result the energy is supplied by anaerobic metabolism for a few minutes. If an effort protocol test is made in steady state for more than $3 \mathrm{~min}$, with independent or intermittent workloads, and employing large muscle groups, what is happening inside the muscles can be measured by capturing respiratory gases at the mouth. In this kind of effort protocol, the plateau will appear in the great majority of the tests. ${ }^{5}$ On the other hand, if the Nervous System stops an effort before a catastrophic failure of homeostasis, observations in necropsy studies and/ or experiments with animals will be necessary, in which this physiological mechanism should be blocked or failed with subsequent death. Considering these trials have not been done yet, the CGM is still a doctrine. Afterwards, every evidence is interpreted based on a specific theory. Thus, it is possible to refuse Professor Noakes' evidences based on Hill's theory, as he has been doing in the opposite way. ${ }^{6}$ 
Another problem is about the ad hoc hypothesis. Theories can only be similar to the truth, and the best one should have many statements and more precise previsions. ${ }^{3}{ }^{4}$ This verisimilitude criterion is determined by subtracting the false content from the true content. That means if every statement has a $50 \%$ probability of being either right or wrong, an extensive theory will have less probability to be accidentally accepted. ${ }^{34}$ New statements and/or corrections may be used to improve this axiomatic theoretical model. But this can only be done under the prima facie axiom. If this first statement is wrong and changes constantly, this is a pseudoscience. ${ }^{3}$ Another way to improve a theory explanation capacity is to change the whole theory for a new one, with a larger number of statements and/or with more precise predictions. Nowadays version of Hill's theory is better than CGM considering these two criteria. ${ }^{17}$ Finally, Professor Noakes made a clear fallacy when he wrote? "In response I argue that the CGM is based on our and others' absolute disproof of the Hill model that has dominated the teaching of the exercise sciences for the past century."

Acknowledgements The author is grateful for Fabiana Eramo for text review.

Funding The authors have not declared a specific grant for this research from any funding agency in the public, commercial or not-for-profit sectors.

Competing interests None declared.

Patient consent Not required.
Provenance and peer review Not commissioned; internally peer reviewed.

Open access This is an Open Access article distributed in accordance with the Creative Commons Attribution Non Commercial (CC BY-NC 4.0) license, which permits others to distribute, remix, adapt, build upon this work non-commercially, and license their derivative works on different terms, provided the original work is properly cited and the use is non-commercial. See: http://creativecommons.org/ licenses/by-nc/4.0/

(c) Article author(s) (or their employer(s) unless otherwise stated in the text of the article) 2018. All rights reserved. No commercial use is permitted unless otherwise expressly granted.

\section{REFERENCES}

1. Robergs RA. Lessons from Popper for science, paradigm shifts, scientific revolutions and exercise physiology. BMJ Open Sport Exerc Med 2017;3:e000226.

2. Kuhn TS. Logic of discovery of psychology of research? Criticism and the growth of knowledge. London, England, UK: Cambridge University Press, 1970:5-32.

3. Popper KR. Conjectures and refutations: the growth of scientific knowledge. New York, USA: Routledge Classics, 2002:3-79.

4. Popper K. The logic of scientific discovery. London and New York: Taylor and Francis e-Library, 2005:27-94; 291-322.

5. Bergh U, Ekblom B, Astrand PO. Maximal oxygen uptake "classical" versus "contemporary" viewpoints. Med Sci Sports Exerc 2000;32:85-8.

6. Pompeu F. Look into central governor Theory. Sports Exer Med Open J 2016;2:62-3.

7. Noakes TD. Response to: Lessons from Popper for science, paradigm shifts, scientific revolutions and exercise physiology. BMJ Open Sport Exerc Med 2018;4:e000277-2.

8. Bassett DR, Howley ET. Limiting factors for maximum oxygen uptake and determinants of endurance performance. Med Sci Sports Exerc 2000;32:70-84. 